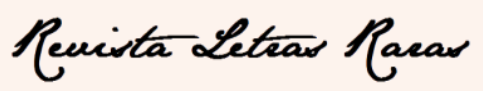

ISSN: 2317-2347 - v. 7, n. 2 (2018)

\title{
Organizadores
}

\section{Roberto Mulinacci}

Roberto Mulinacci (1966) è professore associato confermato di Lingua e Linguistica Portoghese e Brasiliana presso il Dipartimento di Lingue, Letterature e Culture Moderne (LILEC) dell'Università degli Studi di Bologna.

Dopo la laurea in Lingua e Letteratura Portoghese conseguita con il massimo dei voti e la lode presso la Facoltà di Lettere e Filosofia dell'Università degli Studi di Firenze nell'aprile 1993, ha svolto il dottorato di ricerca quadriennale in Iberistica presso l'Università degli Studi di Bologna, conseguendo nel 1998 il titolo di Dottore di Ricerca con una tesi sul romanzo pastorale portoghese, pubblicata poi a Lisbona l'anno successivo per i tipi delle Edições Colibri (Do Palimpsesto ao Texto. A Novela Pastoril Portuguesa).

Collaboratore della cattedra di Lingua e Letteratura Portoghese della Facoltà di Lettere e Filosofia dell'Università degli Studi di Milano nell'a.a. 1997-98, ha ricoperto in seguito l'incarico di professore a contratto di Letteratura Portoghese presso la Scuola Interpreti e Traduttori dell'Università degli Studi di Trieste (a.a. 1998-99), di Letteratura Brasiliana presso l'Università Ca' Foscari di Venezia (a.a. 1998-99 e 1999-2000) e di Lingua e Letteratura Portoghese presso la Facoltà di Lettere e Filosofia dell'Università di Pavia (a.a. 1998-99 e 1999-2000).

Dal 1 gennaio 2001 al 30 settembre 2005, ha svolto le funzioni di Ricercatore di Letteratura Portoghese e Brasiliana (con affidamento) presso la Facoltà di Lingue e Letterature Straniere dell'Università di Bologna. Dal 1 ottobre 2005 è stato chiamato dalla Facoltà di Lingue e Letterature Straniere dell'Università di Bologna a ricoprire il ruolo di professore associato.

Link Currículo:

https://www.unibo.it/sitoweb/roberto.mulinacci/cv 


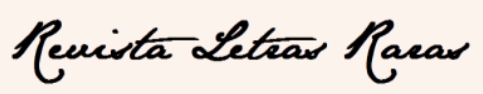

ISSN: 2317-2347 - v. 7, n. 2 (2018)

\section{Sinara de Oliveira Branco}

É Professor Associado da Universidade Federal de Campina Grande, onde atua no Curso de Graduação de Licenciatura em Letras-Inglês e no Programa de Pós-Graduação em Linguagem e Ensino (PPGLE) da Unidade Acadêmica de Letras. Possui Doutorado pelo Programa de Pós-Graduação em Inglês, com pesquisa na área de Tradução, da Universidade Federal de Santa Catarina (2007), Mestrado em Linguística (2002), também pelo Programa de PósGraduação em Inglês da UFSC, com pesquisa na área de Tradução, e Licenciatura em LetrasInglês pela Universidade Federal da Paraíba ? Campus II (1993), atual Universidade Federal de Campina Grande. Foi Coordenadora do Programa de Pós-Graduação em Linguagem e Ensino (PPGLE) da UFCG de novembro de 2012 a abril de 2017. Tem experiência na área de Letras, com ênfase em Linguística e em Tradução, atuando principalmente nos seguintes temas: Tradução e Cultura, Tradução Intersemiótica e Cinema, Didática de Tradução. Foi Conselheira da Secretaria dos Órgãos Deliberativos Superiores (SODS) como representante do Centro de Humanidades. Atualmente é Coordenadora de Pós-Graduação da Pró-Reitoria de Pós-Graduação (PRPG) da UFCG. É líder do Grupo de Pesquisa 'Estudos da Tradução: Teoria, Prática e Formação do Tradutor', do DGP do CNPq. Como pesquisadora, desenvolve e coordena um projeto de pesquisa financiado pelo PaqTcPB/CEEI/UFCG que envolve Tradução, Semiótica e Tecnologia da Informação. É tradutora de artigos científicos no par linguístico inglês-português e português-inglês.

Link Currículo Lattes:

http://lattes.cnpq.br/6023441911258549 


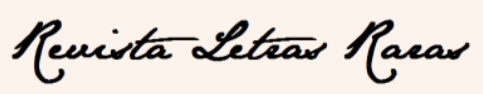

ISSN: 2317-2347 - v. 7, n. 2 (2018)

\section{Pareceristas AD. HOC}

\section{Alessandra Ramos de Oliveira Harden}

Professora do quadro permanente do Departamento de Línguas Estrangeiras e Tradução da Universidade de Brasília desde 1996. Tem experiência na área de Letras, com ênfase em ensino de: traducao (teoria e prática), língua Inglesa, redação e leitura (língua inglesa e portuguesa). Atualmente, realiza pesquisa em história da tradução, tradução de textos feministas e tradução audiovisual, com interesse especial em possibilidades de diálogo com o direito, a história, a educação e a filosofia.

Link Currículo Lattes:

http://lattes.cnpq.br/5623554797211311

\section{Ana Cristina Bezerril Cardoso}

Possui graduação em Direito pela Universidade Federal da Paraíba (1991), especialização em Língua e Literatura Francesa pela Universidade Federal da Paraíba (1996), graduação em Letras - Francês pela Universidade Federal da Paraíba (2000), mestrado em Letras pela Universidade Federal da Paraíba (2007) e doutorado em Estudos da Tradução pela Universidade Federal de Santa Catarina (2015). Atualmente é professor adjunto I da Universidade Federal da Paraíba. Tem experiência na área de Letras e Estudos da Tradução, atuando principalmente nos seguintes temas: Língua Francesa, Teorias da Tradução, História da Tradução no Brasil, Tradução de Fábulas de La Fontaine e tradução de legendas.

Link Currículo Lattes:

http://buscatextual.cnpq.br/buscatextual/visualizacv.do?metodo=apresentar\&id=K4277091U0

\section{Ana Lúcia Maria de Souza Neves}

Possui Doutorado em Literatura Brasileira (2014), pela Universidade Federal da Paraíba, Mestrado em Letras (2001), pela Universidade Federal da Paraíba, Licenciatura Plena em Letras, pela UFPB/UFCG. Atualmente é professora Doutora B-DE da Universidade Estadual da Paraíba. Tem experiência na área de Letras, atuando principalmente nos seguintes temas: Teoria literária, literatura de autoria feminina, literatura infanto-juvenil e literatura e ensino. 


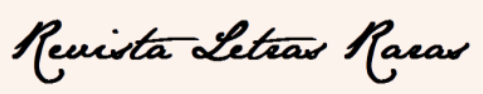

ISSN: 2317-2347 - v. 7, n. 2 (2018)

Link Currículo Lattes:

http://lattes.cnpq.br/9109484291102170

\section{Cleudene de Oliveira Aragão}

Fez sua graduação em Letras pela Universidade Estadual do Ceará (1994) e mestrado em Letras pela Universidade Federal do Ceará (1998). Doutora em Filología Hispánica pela Universitat de Barcelona, onde defendeu em 2006 sua tese sobre Ensino da Literatura na Universidade. Atualmente é professora de língua e literatura espanholas no Curso de Letras e de lingüística aplicada no Programa de Pós-graduação em Lingüística Aplicada da Universidade Estadual do Ceará, atuando em projetos sobre Letramento Literário. Líder do Grupo de Pesquisa Literatura: Estudo, Ensino e (Re) leitura do mundo (GPLEER). Tem experiência na área de Letras, com ênfase em Línguas Estrangeiras Modernas (espanhol e literatura), atuando principalmente nos seguintes temas: Formação de professores, ensino da literatura, formação de leitores, fomento à leitura, ensino de língua espanhola, uso do texto literário no ensino de línguas e letramento literário. Realizou Estágio Pós-doutoral na Faculdade de Educação da Universidade Federal de Minas Gerais, junto ao Grupo de Pesquisa do Letramento Literário -GPELL/ do Centro de Alfabetização, Leitura e Escrita - CEALE (UFMG).

Link Currículo Lattes:

http://lattes.cnpq.br/8597754399627993

\section{Cynthia Beatrice Costa}

Possui graduação em Jornalismo pela Faculdade Cásper Líbero (2002) e mestrado em Literatura e Crítica Literária pela Pontifícia Universidade Católica de São Paulo (2008). É doutora pelo Programa de Pós-Graduação em Estudos da Tradução da Universidade Federal de Santa Catarina (2016), com período sanduíche na Universidade de Yale. É tradutora e possui experiência na área de Estudos da Tradução, Crítica Literária e Comunicação. Atua como professora no curso de Tradução do Instituto de Letras e Linguística (Ileel) da Universidade Federal de Uberlândia (UFU).

Link Currículo Lattes:

http://buscatextual.cnpq.br/buscatextual/visualizacv.do?metodo=apresentar\&id=K4252034P6 


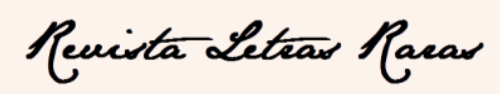

ISSN: 2317-2347 - v. 7, n. 2 (2018)

Doutor em Estudos da Tradução pela Universidade Federal de Santa Catarina (2014) e Mestre em Estudos Linguísticos pela Universidade Federal de Minas Gerais (2006), é Professor Adjunto da Universidade Federal da Paraíba, atuando em ensino e pesquisa relacionados a Tradução e Conflito; Linguística de Corpus, Tecnologia da informação, Linguística Sistêmico-Funcional; e em atividades de extensão na formação de tradutores(as).

Link Currículo Lattes:

http://buscatextual.cnpq.br/buscatextual/visualizacv.do?metodo=apresentar\&id=K4779263Z1

\section{Diógenes André Vieira Maciel}

Possui graduação em Licenciatura Plena Em Letras pela Universidade Federal da Paraíba (1999) e doutorado em Letras pela Universidade Federal da Paraíba (2003). Atualmente é professor doutor - d da Universidade Estadual da Paraíba. Tem experiência na área de Letras, com ênfase em Letras, atuando principalmente nos seguintes temas: dramaturgia brasileira, teatro brasileiro, nacional-popular, drama moderno e classes subalternas.

Link Currículo Lattes:

http://lattes.cnpq.br/0181025251506730

\section{Elaine Espindola Baldissera}

Possui graduação em Letras Habilitação Plena Em Inglês Português pela Universidade do Oeste de Santa Catarina (2000). Também possui Mestrado e Doutorado em Letras (Inglês e Literatura Correspondente) pela Universidade Federal de Santa Catarina (2005 e 2010, respectivamente). Obteve seu Pós-doutorado na The Hong Kong Polytechnic University onde trabalhou sob a orientação do Professor Christian M.I.M. Matthiessen no projeto intitulado Translator's Education: From a Vocational into a more Grammar Based Approach. Trabalhou como Professora Assistente na The Hong Kong Polytechnic University onde atuou nas áreas de Lingüística Aplicada, Tradução, Aquisição de Segunda Língua, World Englishes, Análise do Discurso, entre outras. Trabalhou também como Professora Adjunta da Pontificia Universidad Católica de Valparaíso (PUCV) onde ministrou aulas para cursos de graduação no Departamento de Traducción e Interpretación e classes de pós-graduação no Departamento de Lingüística. Atualmente é Professora Adjunta da Universidade Federal da Paraíba (UFPB)/CCHLA/DLEM. É participante do Grupo de Pesquisa em Linguística Forense na UFSC, do Núcleo de Estudos em Língua Portuguesa (NELP-UFSM), do Systemic Across Languages (SAL) e do GEPLAM. Suas áreas de interesse são: Linguística Sistêmico- 


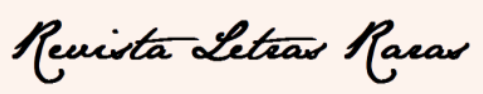

ISSN: 2317-2347 - v. 7, n. 2 (2018)

Funcional; Análise do Discurso; Estudos da Tradução; Inglês como segundo língua; Tipologia Textual.

Link Currículo Lattes:

http://lattes.cnpq.br/0037079253908368

\section{Elizabeth Christina de Andrade Lima}

Possui Bacharelado em Ciências Sociais, com área de concentração em Antropologia, pela Universidade Federal da Paraíba (1986), Mestrado em Sociologia Rural pela Universidade Federal da Paraíba (1992) e Doutorado em Sociologia, na linha de pesquisa Sociologia da Cultura, pela Universidade Federal do Ceará (2001). Atualmente é professora Titular de Antropologia na Universidade Federal de Campina Grande. Desenvolve pesquisas nas seguintes áreas: Gênero e Política, Cultura e Política, Voto e Comportamento Eleitoral, com ênfase em estudos de antropologia da política, a mulher e a disputa por espaços de poder, cotidiano da política, política no ciberespaço. É credenciada nos Programas de Pós-Graduação em Ciências Sociais e História da UFCG, orienta alunos do doutorado e do mestrado. É líder do Grupo de Pesquisa: Antropologia da Política, Cultura Midiática e Práticas Políticas, membro do Grupo de Estudo Núcleo de Estudos Paranaense e Coordenadora do Laboratório de Estudos sobre Cultura, Mídia e Política - LECMIPO, além de Membro do Laboratório de Pesquisas em Política e Cultura - LEPEC, da UFC.

Link Currículo Lattes:

http://lattes.cnpq.br/9483143620752293

\section{Genilda Azerêdo}

Possui graduação em Licenciatura Plena em Letras pela Universidade Federal da Paraíba (1985), Especialização em Literatura Anglo-Americana (1986), Mestrado em Letras pela Universidade Federal da Paraíba (1990) e Doutorado em Letras (Inglês e Literaturas de língua inglesa) pela Universidade Federal de Santa Catarina (2001). Atualmente é professora Titular da Universidade Federal da Paraíba. Tem experiência na área de Letras, com ênfase em Literaturas Estrangeiras Modernas, atuando principalmente nas seguintes áreas: cinema e literatura; adaptação fílmica; teorias da narrativa literária e fílmica; narrativas poéticas.

Link Currículo Lattes:

http://buscatextual.cnpq.br/buscatextual/visualizacv.do?metodo=apresentar\&id=K4785466Z8 


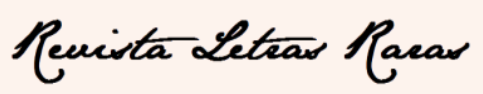

ISSN: 2317-2347 - v. 7, n. 2 (2018)

\section{Gilles Jean Abes}

É Professor Adjunto na Universidade Federal de Santa Catarina (UFSC- Florianópolis) desde 2014/2, no Departamento de Língua e Literatura Estrangeiras (DLLE), e professor permanente do programa de Pós-Graduação em Estudos da Tradução (PGET-UFSC). Realizou um Pós-doutorado em Estudos da Tradução de 2011/2 a 2013/1 pelo mesmo programa. É Doutor na área de Estudos da Tradução pela PGET/UFSC desde 2011. Tornouse Mestre em Teoria Literária (julho 2007) pela mesma universidade. Tem licenciatura em Letras - Francês também na UFSC. É tradutor.

Link Currículo Lattes:

http://buscatextual.cnpq.br/buscatextual/visualizacv.do?metodo=apresentar\&id=K4251551T1

\section{Girlene Moreira da Silva}

Possui graduação em Letras - Português e Espanhol (2008), mestrado em Linguística Aplicada (2011) e doutorado em Linguística Aplicada (2016) pela Universidade Estadual do Ceará. Atualmente é professora efetiva de língua espanhola do Instituto Federal de Educação, Ciência e Tecnologia do Rio Grande do Norte (IFRN), atuando nos Cursos de Licenciatura em Espanhol dos Campi Natal Central e EaD. Tem experiência em pesquisas na área de Linguística Aplicada, atuando principalmente nos seguintes temas: formação de professores de línguas, crenças, ensino de Espanhol como língua estrangeira, ensino de leitura e uso do texto literário no ensino de línguas estrangeiras.

Link Currículo Lattes:

http://lattes.cnpq.br/8122463467348141

\section{José Edilson Amorim}

Fez graduação em Letras - Licenciatura Plena - na Universidade Federal da Paraíba (1979); realizou Mestrado em Letras na UFPB (1989), na Área de Concentração em Literatura Brasileira, e cursou o Doutorado em Letras na mesma instituição e na mesma área de Concentração (1998). Professor da UFPB desde 1983, atualmente é professor associado da Universidade Federal de Campina Grande, com atuação na Unidade Acadêmica de Letras, onde dá aulas de Literatura e desenvolve atividades de pesquisa com os seguintes temas: literatura e sociedade; leitura do do texto literário: análise e interpretação; Machado de Assis e o século XIX no Brasil; literatura regionalista (Graciliano Ramos e José Lins do Rêgo entre outros autores brasileiros). 


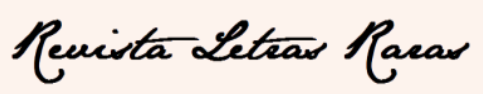

ISSN: 2317-2347 - v. 7, n. 2 (2018)

Link Currículo Lattes:

http://buscatextual.cnpq.br/buscatextual/visualizacv.do?metodo=apresentar\&id=K4703668T5

\section{Julio Cesar Neves Monteiro}

Tem Pós-doutorado em Estudos da Tradução pela Vrije Universiteit Brussel,na Bélgica, PósDoutorado em Estudos da Tradução pela Universidade Federal de Santa Catarina e Doutorado em Literatura pela Universidade Federal de Santa Catarina. É Professor Adjunto no Departamento de Línguas Estrangeiras e Tradução da Universidade de Brasília, onde atua no Programa de Pós-Graduação em Estudos da Tradução e no curso de Tradução PortuguêsEspanhol. Coordena o Núcleo de Estudos de Línguas e Culturas Germânicas da Universidade de Brasília. Tem experiência na área de Letras, com ênfase em Estudos da Tradução e Literatura Comparada.

Link Currículo Lattes:

http://buscatextual.cnpq.br/buscatextual/visualizacv.do?metodo=apresentar\&id=K4798139J1

\section{Luana Ferreira de Freitas}

Concluiu doutorado em Teoria Literária, na Universidade Federal de Santa Catarina, em 2007, e pós-doutorado em Estudos da Tradução, na Vrije Universiteit Brussel, em 2018 e na Universidade Federal de Santa Catarina, em 2010 . É atualmente professora na Universidade Federal do Ceará, onde atua na área de literatura inglesa e Estudos Literários da Tradução, em especial, autoria e estilo. Desenvolve atualmente as pesquisas: "Tradução Comentada e Anotada" e "Internacionalização da literatura brasileira: Machado de Assis, Clarice Lispector, Guimarães Rosa e Graciliano Ramos". É uma das fundadoras e primeira coordenadora da POET - Pós-Graduação em Estudos da Tradução (UFC), vice-coordenadora do GT de Estudos da Tradução da ANPOLL, gestão 2014-2016,coordenadora do GT de Estudos da Tradução de 2018-2020, membro da CLIV (Centrum voor Literatuur in vertaling) desde 2017.

Link Currículo Lattes:

http://buscatextual.cnpq.br/buscatextual/visualizacv.do?metodo=apresentar\&id=K4760270D6

\section{Luciane Leipnitz}

Possui Bacharelado em Letras pela Universidade Federal do Rio Grande do Sul (2001), mestrado e doutorado em Letras pela Universidade Federal do Rio Grande do Sul (2005, 2010). Atualmente é professora adjunta do Curso de Bacharelado em Tradução na 


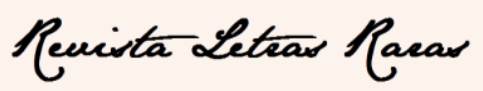

ISSN: 2317-2347 - v. 7, n. 2 (2018)

Universidade Federal da Paraíba/João Pessoa/PB. Tem experiência na área de Letras e Linguística, com ênfase em Estudos da Tradução e Línguas Estrangeiras Modernas, atuando principalmente nos seguintes temas: Ensino de Tradução, Linguistica de Corpus, Língua Alemã, Lexicografia e Terminologia.

Link Currículo Lattes:

http://buscatextual.cnpq.br/buscatextual/visualizacv.do?metodo=apresentar\&id=K4736805E0

\section{Marcia Candeia Rodrigues}

Possui graduação em Letras pela Universidade Potiguar (1999), mestrado em Linguística Aplicada pelo Programa de Pós-Graduação em Estudos da Linguagem da Universidade Federal do Rio Grande do Norte (2003) e é doutora pelo Programa de Pós-graduação da Universidade Federal de Pernambuco - Universidade Nova de Lisboa. Atualmente, é professora adjunta da Universidade Federal de Campina Grande no Centro de Humanidades $\mathrm{CH}$ - Campina Grande- Pb. Tem experiência na área de Linguística e Língua Portuguesa, com ênfase em Linguística Aplicada, atuando principalmente nos seguintes temas: ensino e aprendizagem da escrita, crenças e estratégias de aprendizagem da escrita, aspectos sintáticos e morfossintáticos da língua portuguesa, letramento, saberes e práticas pedagógica.

Link Currículo Lattes:

http://lattes.cnpq.br/9787353864767301

\section{Marcílio Garcia de Queiroga}

Possui Mestrado em Literatura e Cultura pelo Programa de Pós-Graduação em Literatura (PPGL), da Universidade Federal da Paraíba (2005) e Doutorado em Estudos da Tradução pela Pós-Graduação em Estudos da Tradução (PGET), da Universidade Federal de Santa Catarina. Seu interesse reside nas seguintes áreas de pesquisa: ensino e aprendizagem de língua inglesa, tradução de literatura infantojuvenil, voz do tradutor, estudos com base em corpora e tradução e ensino.

Link Currículo Lattes:

http://buscatextual.cnpq.br/buscatextual/visualizacv.do?metodo=apresentar\&id=K4537884Z3

\section{Marie Hélène Torres}




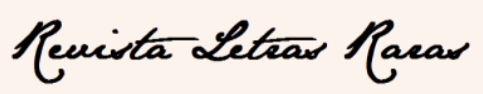

ISSN: 2317-2347 - v. 7, n. 2 (2018)

É Professora Titular da Universidade Federal de Santa Catarina onde atua na graduação em Letras Estrangeiras e no Programa de Pós-Graduação em Estudos da Tradução. Possui PósDoutorado pela Universidade de Minas Gerais (2011), Doutorado em Estudos em Tradução Katholieke Universiteit Leuven (2001), Mestrado em Literatura pela Universidade Federal de Santa Catarina (1995) e Licenciatura Dupla Portugues-Francês pela Universidade Federal de Santa Catarina (1992). Coordena um projeto de pesquisa com verba do CNPq (2013-2016) sobre antologia e literatura francesa (http://mnemosineantologias.com) Foi coordenadora da Pós-Graduação em Estudos da Tradução da UFSC de 2003 a 2007; coordenadora da Especialização em Formação de Professores de Tradução Literária de 2008 a 2009, coordenadora do Doutorado Interinstitucional (DINTER) da PGET/UFSC com a UFPB e a UFCG de 2010 a 2014 e atualmente coordenadora do Doutorado Interinstitucional (DINTER) da PGET/UFSC com a UFPA de 2015 a 2019. Foi vice-coordenadora do GT de Tradução da ANPOLL em 2012-2014 e membro da Diretoria da ABRAPT da gestão 2011-2013. Tem experiência na área de Letras, com ênfase em Literatura e em Tradução, atuando principalmente nos seguintes temas: literatura nacional e literatura traduzida, teoria e história da tradução, literatura de língua francesa traduzida no Brasil e estudos em tradução. Publicou recentemente entre outros Variations sur l'étranger dans les lettres: cent ans de traductions françaises des lettres brésiliennes (2004, pela Artois Presses Université), Literatura Traduzida/Literatura Nacional (em co-autoria, pela 7Letras em 2008), o Dicionário de Tradutores Literários do Brasil (em co-autoria online), Literatura e tradução : textos selecionados de José Lambert (em co-autoria, pela 7Letras em 2011), Traduzir o Brasil Literário : paratexto e discurso de acompanhamento, vol 1 (2011), Traduzir o Brasil Literário : Historia e crítica, vol.2 (2014). Traduziu A tradução e a letra ou o albergue do longinquo de Antoine Berman (1a ed. em 2007 e 2a ed. em 2013), Tradução da Teoria dos Clássicos Francês-Português (em co-autoria, Copiart, 2018). É co-diretora da Coleção TransLetras desde 2015. Como pesquisadora desenvolve um projeto sobre as contistas francesas do século das Luzes. É também tradutora de literatura infantil e juvenil.

Link Currículo Lattes:

http://buscatextual.cnpq.br/buscatextual/visualizacv.do?metodo=apresentar\&id=K4728710P0

\section{Marta Pragana Dantas}

Licenciada em Letras (Português e Francês) pela Universidade Católica de Pernambuco (1984), possui mestrado em Teoria da Literatura pela Universidade Federal de Pernambuco (1994), doutorado em Literatura Francesa pela Universidade Paris III / Sorbonne-Nouvelle (2004) e pós-doutorado na École des Hautes Études en Sciences Sociales - Centre de Sociologie européenne - CSE (2014-2015). Atualmente é professora associada no Departamento de Letras Estrangeiras Modernas e no Programa de Pós-Graduação em Letras (PPGL) da UFPB. É vice-presidente da Associação Brasileira de Pesquisadores em Tradução - ABRAPT (2017-2019). É também editora-chefe da Revista Graphos. Tem experiência no 


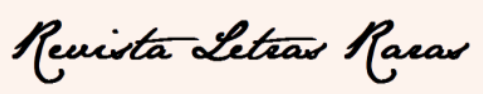

ISSN: 2317-2347 - v. 7, n. 2 (2018)

ensino de Francês Língua Estrangeira, Literatura Francesa, Teoria da Literatura e Tradução. Atua principalmente nos seguintes temas: estudos da tradução, literatura francesa e teoria da literatura.

Link Currículo Lattes:

http://buscatextual.cnpq.br/buscatextual/visualizacv.do?metodo=apresentar\&id=K4785821U9

\section{Patrícia Rodrigues Costa}

Doutora em Estudos da Tradução (2018) pela Universidade Federal de Santa Catarina (UFSC), bolsista CAPES-DS, com estágio doutoral (CAPES ? PDSE) na Université de Montréal (UdeM), Canadá, sob orientação do Prof. Dr. Georges L. Bastin. Participou, durante o doutoramento, do Programa Futuros Líderes das Américas (Programme des futurs leaders dans les Amériques - PFLA) com estágio de pesquisa na Université de Montréal (UdeM), Montréal - Canadá, sob orientação do Professor Doutor Álvaro Echeverri (21/08/2014 25/02/2015). Mestre em Estudos da Tradução (2013) pela Universidade de Brasília (UnB). Bacharel em Letras /Tradução - Inglês (2008), tendo sido bolsista de iniciação científica, e Agronomia (2014) pela mesma universidade. Colabora com a Revista Belas Infiéis (ISSN 2316-6614) desde sua criação em 2011. É editora-assistente da Revista Belas Infiéis desde 2013. Atuou como revisora no periódico Cadernos de Tradução (ISSN 2175-7968) e Revista da ANPOLL (ISSN 1982-7830) e como parecerista ad hoc do periódico Mutatis Mutandis (ISSN 2011-799X). Foi tradutora do francês para o português do Programa Saint Hilaire (CAPES/França - 2014/2015), com capítulos de livro publicados pela OPEN EDITION BOOKS (Marseille, França). É colaboradora do Instituto Nacional de Estudos e Pesquisas Educacionais Anísio Teixeira (Inep) desde 2016 e atua como consultora ad hoc da Fundação de Amparo à Pesquisa do Distrito Federal (FAP-DF). Tem experiência na área de editoração de periódicos acadêmicos e na área de Letras com ênfase nos Estudos da Tradução, atuando nos seguintes temas: formação de tradutores, estudos curriculares e literatura traduzida.

Link Currículo Lattes:

http://buscatextual.cnpq.br/buscatextual/visualizacv.do?metodo=apresentar\&id=K4235914P7

\section{Rafael Campos Quevedo}

Doutor em Literatura pela Universidade de Brasília (UnB); mestre em Letras pela Universidade Federal do Espírito Santo (UFES), especializado em Literatura Brasileira (UNIVERSO) e graduado em Filosofia e Letras pela Universidade Federal do Maranhão (UFMA). Atua na área de Literatura Portuguesa e Brasileira. Desenvolve pesquisa em Poesia Contemporânea de Língua Portuguesa. Professor Adjunto do Departamento de Letras da 


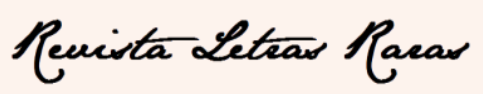

ISSN: 2317-2347 - v. 7, n. 2 (2018)

Universidade Federal do Maranhão (UFMA). Professor permanente do Programa de PósGraduação em Letras da UFMA (PGLetras-UFMA).

Link Currículo Lattes:

http://lattes.cnpq.br/5672071201353574

\section{Roberto Carlos de Assis}

Possui graduação em Letras - inglês (1991), mestrado em Linguística Aplicada (2004) e doutorado em Linguística Aplicada, com ênfase em Estudos da Tradução (2009), todos pela Universidade Federal de Minas Gerais, com estágio SWE na Universidade de Lisboa (out 2007/out 2008) e pós-doutorado no POSTRAD/ UnB - Programa de Pós-Graduação em Estudos da Tradução. Foi coordenador do curso de Bacharelado em Tradução da UFPB (2010/2012) e Chefe dos Departamentos de Letras Estrangeiras Modernas (abr/2012 a abr/2014) e de Mediações Interculturais (Dez 2014/ Julho 2016) do Centro de Ciências Humanas Letras e Artes da UFPB. Atualmente é vice coordenador do Programa de Pós Graduação em Letras da UFPB; Colaborador no programa de Pós-Graduação em Estudos Linguísticos (PosLin/FALE/UFMG); pesquisador colaborador do POSTRAD/UNB; co-editor da Revista Graphos;e. Presidente da Associação Brasileira de Pesquisadores em Tradução ABRAPT (2017-2019). Participa(ou) de grupos de pesquisa na UFCG, UFPB, UFMG e UnB. É membro do corpo editorial de vários periódicos e atua principalmente nos seguintes temas: Língua inglesa, Estudos da Tradução, Literatura Traduzida, Linguística Sistêmico-Funcional, Representação de Atores Sociais.

Link Currículo Lattes:

http://buscatextual.cnpq.br/buscatextual/visualizacv.do?metodo=apresentar\&id=K4734886J8

\section{Rosângela de Melo Rodrigues}

Professora Adjunta da Universidade Federal de Campina Grande desde 1995. Doutora em Literatura e Interculturalidade (UEPB - 2015). Mestre em Literatura e Cultura (UFPB - 2005). Especialista em Língua Portuguesa e Literatura Brasileira (UFPB - 1992). Graduada em Licenciatura Plena em Letras (UFPB - 1991).

Link Currículo Lattes:

http://buscatextual.cnpq.br/buscatextual/visualizacv.do?metodo=apresentar\&id=K4799485U7 


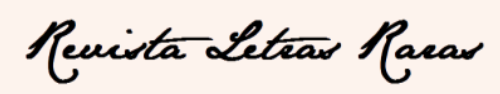

ISSN: 2317-2347 - v. 7, n. 2 (2018)

\section{Sérgio Romanelli}

Professor Doutor, classe Associado I DE, no Departamento de Língua e Literatura Estrangeiras, nas Pós-graduações em Literatura e Linguística da Universidade Federal de Santa Catarina. Bolsista em produtividade PQ-2 do CNPq. Possui graduação em Letras e Filosofia - Università Degli Studi di Milano (1997), Mestrado e Doutorado em Linguística Aplicada pela UFBA (2003 e 2006), Pós-doutorado em Antropologia da tradução pela Antwerp University (2014). Tem experiência na área de Linguística aplicada ao ensino/aprendizagem de LE e tradução e em Crítica Genética, atuando principalmente nos seguintes temas: Línguas Estrangeiras Modernas, Crítica Genética, Linguística Aplicada e Tradução. É líder do grupo de pesquisa "Estudos Linguísticos e aquisição/aprendizagem do italiano como língua estrangeira" do CNPq. Presidente da APCG (Associação dos Pesquisadores em Crítica Genética do Brasil) de 2012 a 2015. Editor-Chefe das revistas MANUSCRÍTICA (QUALIS A2) e IN-TRADUÇÕES (QUALIS B3) de 2012 s 2015 a primeira e de 2010 a 2015 a segunda. Coordenador do NUPROC - Núcleo de Estudo de Processos Criativos (www.nuproc.cce.ufsc.br), membro do Núcleo ONETTI. Tradutor (Virgillito, Alberti, Speroni, Espanca,Twain, etc.) poeta e cantor.

Link Currículo Lattes:

http://buscatextual.cnpq.br/buscatextual/visualizacv.do?metodo=apresentar\&id=K4753735Z0

\section{Walter Carlos Costa}

Walter Carlos Costa estudou Filologia Românica (Francês e Espanhol) na Katholieke Universiteit Leuven, Bélgica; tem doutorado sobre as traduções de Jorge Luis Borges para o inglês pela University of Birmingham, Reino Unido, e pós-doutorado pela UFMG. É Professor Titular aposentado do Departamento de Língua e Literatura Estrangeiras da Universidade Federal de Santa Catarina, onde atua na PGET (Pós-Graduação em Estudos da Tradução). Pesquisador do CNPq, pesquisa literatura hispano-americana (sobretudo a obra de Jorge Luis Borges), literatura comparada, estudos da tradução (especialmente a conexão entre literatura traduzida e literatura nacional) e literatura fantástica. Foi presidente da ABRAPT (Associação Brasileira de Pesquisadores em Tradução) na gestão 2010-2013. Esteve em colaboração técnica no Departamento de Letras Estrangeiras da Universidade Federal do Ceará de agosto de 2013 a julho de 2016. Atualmente é Professor Visitante na POET (PósGraduação em Estudos da Tradução), da Universidade Federal do Ceará.

Link Currículo Lattes:

http://buscatextual.cnpq.br/buscatextual/visualizacv.do?metodo=apresentar\&id=K4781713H2 


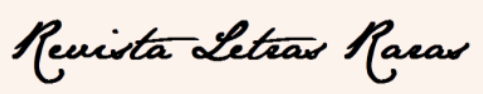

ISSN: 2317-2347 - v. 7, n. 2 (2018)

\section{Williany Miranda da Silva}

Professora associada da Unidade Acadêmica de Letras e membro do Programa de Pós Graduação em Linguagem e Ensino da Universidade Federal de Campina Grande. Possui mestrado e doutorado em Letras pela Universidade Federal de Pernambuco e atua na área de Linguística, com ênfase em Leitura e Produção de Textos, destacando-se os seguintes temas: materiais didáticos, ambientes digitais, concepções de ensino, formação docente, livro didático, escrita e oralidade. Com estágio de pós-doutoramento concluído pela Universidade Federal de Minas Gerais (2013), atualmente desenvolve projetos de pesquisa; envolvendo tecnologias, linguagens, gêneros textuais orais e escritos e atuação docente, com orientações tanto na pós-graduação quanto na graduação, em programas PIBIC e PIBID- Letras, em que atuou como coordenadora do subprojeto PIBID-LETRAS, de 2016-2018. Membro do grupo de pesquisa Teorias da linguagem e ensino, na linha de pesquisa Lingua(gem) em contexto de ensino de português.

Link Currículo Lattes:

http://lattes.cnpq.br/0044907035446244 